\title{
Confirmation of Anopheles (Anopheles) calderoni Wilkerson, 1991 (Diptera: Culicidae) in Colombia and Ecuador through molecular and morphological correlation with topotypic material
}

\author{
Ranulfo González ${ }^{1 /+}$, Nancy Carrejo ${ }^{1}$, Richard C Wilkerson², Joubert Alarcon ${ }^{3}$, \\ Joubert Alarcon-Ormasa ${ }^{3}$, Fredy Ruiz ${ }^{2,4}$, Ravinder Bhatia ${ }^{4}$, José Loaiza ${ }^{5,6}$, Yvonne-Marie Linton ${ }^{4}$ \\ ${ }^{1}$ Facultad de Ciencias Naturales y Exactas, Universidad del Valle, Edificio 320, Ciudadela Universitaria Meléndez, Cali, Colombia \\ ${ }^{2}$ Walter Reed Biosystematics Unit, Museum Support Center, Smithsonian Institution, Suitland, MD, USA \\ ${ }^{3}$ Servicio Nacional de Control de Enfermedades Transmitidas por Vectores Artrópodos, Ministerio Salud Publica, Guayaquil, Ecuador \\ ${ }^{4}$ Natural History Museum, London, England ${ }^{5}$ Programa Centroamericano de Maestría en Entomología, Vicerrectoría de Investigación y \\ Postgrado, Universidad de Panama, Republic of Panama ${ }^{6}$ Smithsonian Tropical Research Institute, Balboa Ancon, Republic of Panama
}

The morphologically similar taxa Anopheles calderoni, Anopheles punctimacula, Anopheles malefactor and Anopheles guarao are commonly misidentified. Isofamilies collected in Valle de Cauca, Colombia, showed morphological characters most similar to An. calderoni, a species which has never previously been reported in Colombia. Although discontinuity of the postsubcostal pale spots on the costa $(C)$ and first radial $(R$,$) wing veins is purportedly diagnostic$ for An. calderoni, the degree of overlap of the distal postsubcostal spot on $C$ and $R_{1}$ were variable in Colombian specimens (0.003-0.024). In addition, in 98.2\% of larvae, seta 1-X was located off the saddle and seta 3-C had 4-7 branches in $86.7 \%$ of specimens examined. Correlation of DNA sequences of the second internal transcribed spacer and mtDNA cytochrome c oxidase subunit I gene (COI) barcodes (658 bp of the COI gene) generated from Colombian progeny material and wild-caught mosquitoes from Ecuador with those from the Peruvian type series of An. calderoni confirmed new country records. DNA barcodes generated for the closely related taxa, An. malefactor and An. punctimacula are also presented for the first time. Examination of museum specimens at the University of the Valle, Colombia, revealed the presence of An. calderoni in inland localities across Colombia and at elevations up to $1113 \mathrm{~m}$.

Key words: Anopheles calderoni - morphology - DNA barcodes - COI - ITS2 - Colombia - Ecuador - new country records

The Central and Southern American mosquito species Anopheles (Anopheles) calderoni Wilkerson, 1991, Anopheles (Anopheles) guarao Anduze and Capdevielle (1949), Anopheles (Anopheles) malefactor Dyar \& Knab 1907 and Anopheles (Anopheles) punctimacula Dyar \& Knab 1906 (Arribalzagia Series, Laticorn Section) (Harbach 2004) are highly isomorphic and closely related (Wilkerson 1990, 1991). Following reassessment of specimens from both the type series and type locality [Panama, Colon (Canal Zone)] of An. punctimacula, Wilkerson (1990) detected exemplars of An. malefactor in the syntype series and resurrected the nominal species from synonymy with the former. According to Wilkerson (1990, 1991), An. punctimacula is reported from Mexico to northern Colombia and Venezuela, whereas An. malefactor appears to be limited to Panama and northeastern Colombia. So far, the distribution of An. guarao is thought to be limited to its type locality of Caripito, Estado Monagas, Venezuela (Anduze \& Capdevielle 1949).

Financial support: Royal Caribbean International, Consortium for the Barcode of Life, The Sloane Foundation, The ScholarShip Program LLC + Corresponding author: ranulfog@gmail.com

Received 29 April 2010

Accepted 31 August 2010
Further assessment of An. punctimacula s.l. specimens from Piura, Salitral, Peru, revealed yet another cryptic species, which Wilkerson (1991) formally named An. calderoni. The description suggested that prior records of An. punctimacula in the low-lying areas $(<250 \mathrm{~m})$ of the Pacific Coast of Colombia, Ecuador and Peru (LeviCastillo 1949, Russell et al. 1963, Calderón et al. 1974) could, at least in part, refer to An. calderoni. Based on characters of the adult females, Rubio-Palis and Moreno (2003) confirmed An. calderoni from the states of Táchira and Barinas, in Venezuela. In light of this geographical discordance, its presence in Colombia and Ecuador seems highly likely. That An. calderoni has been found positive for Plasmodium vivax in the Peruvian regions of Lima, Salitral, Querecotillo, Lourdes Paz and Palo Blanco (Kroeger \& Alarcón 1993, Calderón et al. 1995), makes this taxonomic query also one of biomedical importance.

Literature records and museum holdings indicate only the presence of An. punctimacula and An. malefactor in Colombia (González \& Carrejo 2007), and the morphological keys most commonly used to identify Colombian Anopheles (Suárez et al. 1988) predate the description of An. calderoni. Following the detection of atypical An. punctimacula s.l. specimens from various localities in the valley of the Rio Cauca, progeny broods were obtained to facilitate a thoroughly integrated systematic assessment of these Colombian variants. Identifications of archive specimens of An. punctimacula s.l. in the Entomological Museum, Universidad del Valle, Colombia (MUSENUV) were revised, alongside wildcaught material from Ecuador. 


\section{MATERIALS AND METHODS}

Specimens - Wild-caught adult females of An. punctimacula s.l. were collected in August 2007, between 18 $\mathrm{pm}-21 \mathrm{pm}$, either resting or in human landing catches, at Corporacion Autonoma Regional del Valle del Cauca in Laguna de Sonso, Buga, Valle del Cauca, Colombia $\left(03^{\circ} 52^{\prime} 32^{\prime \prime} \mathrm{N}, 76^{\circ} 20^{\prime} 53^{\prime \prime} \mathrm{W}\right)$ at an elevation of $960 \mathrm{~m}$. Females were induced to oviposit according to the standard protocols of Belkin et al. (1965) and once eggs were laid, females were pinned and stored in the MUSENUV collections and labelled with the same code as the corresponding progeny. Larvae were fed on a mix of brewer's yeast and rabbit food. Some 4th instar larvae were separated, killed by boiling water and stored in acetic acid, glycerol and alcohol fixative (10 parts $60 \%$ ethyl alcohol with 1 part glacial acetic acid and 1 part glycerol) for future morphological examination. Larval and pupal exuviae of link-reared specimens were stored in $75 \%$ ethanol prior to slide-mounting following the protocols in González and Carrejo (2007). Emergent adults were allowed to feed on $10 \%$ sucrose solution and were later killed by freezing. Adults were pinned and labelled with the same code as the mother for further integrated studies.

Morphological assessment - Morphological identifications were carried out using the diagnostic characters for An. punctimacula s.l. (Wilkerson 1990) and the original species description of An. calderoni (Wilkerson 1991). Wing character nomenclature used herein follows that of Wilkerson and Peyton (1990) (Fig. 1, Tables I-III). Measurements were taken using a micrometer mounted in a Nikon SMZ-645 Stereo Zoom Microscope. For each female $(n=79)$, variation in the overlap of the postsubcostal dark spot with the preapical dark spot (Table I), the respective lengths of the costal wing spots (Table II) and the ratio of the length of the costal wing spot relative to the total wing length (measured from the humeral cross-vein) (Table III) were calculated. The presence of key diagnostic characters of An. calderoni larvae - numbers of branches on seta 3-C and the positioning of seta 1 -X in relation to the saddle (Wilkerson 1991) - were assessed in all mounted larvae $(\mathrm{n}=144)$ (Table IV). Verification of specimens held in the archive collections of the MUSENUV and which had been identified as An. punctimacula were also reassessed (Supplementary data).

Molecular analysis - Full locality details of specimens used in the molecular part of this study are given in Table V. DNA extraction, polymerase chain reaction (PCR) amplification and product clean-up took place on board The ScholarShip (M/V Oceanic II) as part of the activities of the Mosquito Barcoding Initiative (MBI). DNA was extracted from the abdomens of pinned specimens using the QIAGEN ${ }^{\circledR}$ BioSprint robotic DNA extraction machine and the BioSprint 96 DNA Tissue Kit (QIAGEN ${ }^{\circledR}$, Crawley, UK), following the manufacturers instructions. The universal LCO and HCO barcoding primers of Folmer et al. (1994) were used to amplify the cytochrome c oxidase subunit I gene (COI) region (658 bp, less primers). The PCR comprised $1 \mu \mathrm{L}$ template DNA, $1 \mu \mathrm{L} 10 \times \mathrm{NH}_{4}$ buffer, $0.5 \mu \mathrm{L}$ dNTPs at $2.5 \mathrm{mM}$,
$0.3 \mu \mathrm{L}$ each primer at $10 \mu \mathrm{M}, 0.4 \mu \mathrm{L} \mathrm{MgCl}_{2}$ at $50 \mathrm{mM}$ and $0.2 \mu \mathrm{L}$ of Taq polymerase (BioLine, London, England), made up to $10 \mu \mathrm{L}$ with $\mathrm{ddH}_{2} 0$. The PCR reaction comprised initial denaturing at $95^{\circ} \mathrm{C}$ for $5 \mathrm{~min}$, then 34 cycles of $95^{\circ} \mathrm{C}$ for $30 \mathrm{~s}, 48^{\circ} \mathrm{C}$ for $30 \mathrm{~min}$ and $72^{\circ} \mathrm{C}$ for $45 \mathrm{~s}$, followed by a 5 -min extension at $72^{\circ} \mathrm{C}$ and a $10^{\circ} \mathrm{C}$ hold. Two microliter of each PCR product was visualized on $1 \%$ agarose gels, containing $0.5 \mathrm{mg} / \mathrm{mL}$ of ethidium bromide. Amplification of the nuclear ITS2 rDNA region was achieved using the 5.8SF and 28SR primers of Collins and Paskewitz (1996), following the protocol listed in Linton et al. (2001).

PCR products were purified using ExoSAP-IT ${ }^{\circledR}$ (USB, Cleveland, Ohio), following the manufacturers instructions. Bi-directional DNA sequences were generated either in the Sequencing Facility of the Natural History Museum, London, or at the Museum Support Center of the Smithsonian Institution, Maryland, using the Big Dye ${ }^{\circledR}$ Terminator Kit (PE Applied Biosystems, Warrington, England) and run on ABI 3730 automated sequencers (PE Applied Biosystems). Sequences were edited using

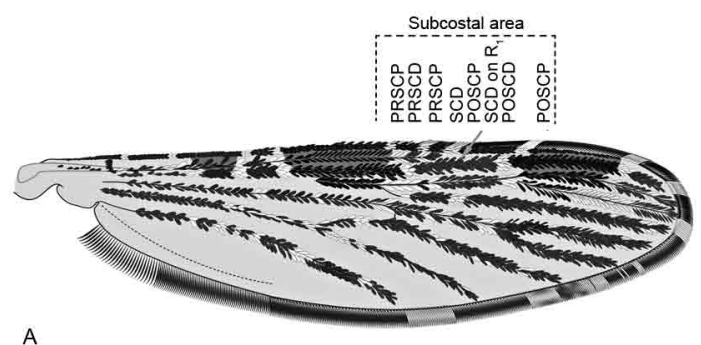

A
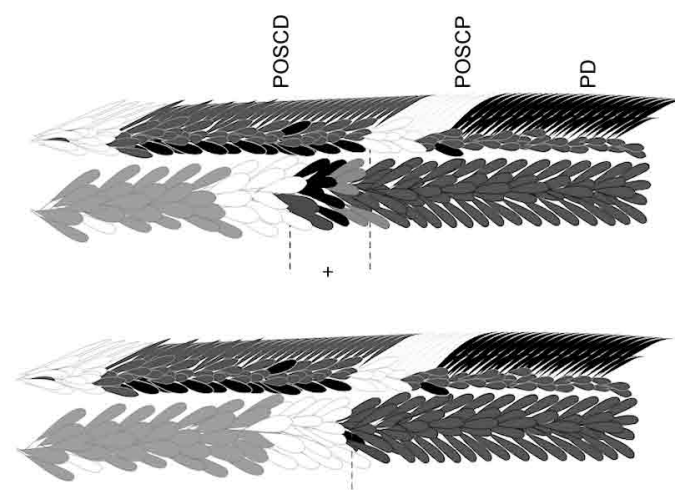

0

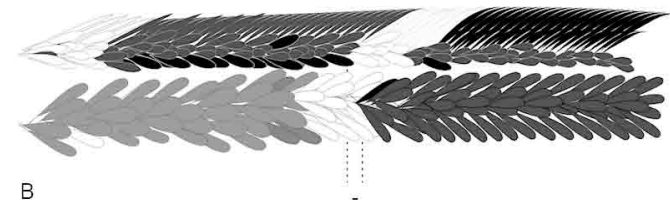

Fig. 1: schematic diagram of the wing of Anopheles calderoni. A: the position of postsubcostal pale spot (POSCP) with relation to its position on the first radial vein $\left(\mathrm{R}_{1}\right)$; $\mathrm{B}$ : variation in the position of the POSCP with regard to its reportedly standard position on $\mathrm{R}_{1}$. PD: preapical dark; POSCD: postsubcostal dark. PRSCD: presubcostal dark; PRSCP: presubcostal pale; SCD: subcostal dark. 
TABLE I

Variation in the extent of overlap (in $\mathrm{mm}$ ) of the distal part of postsubcostal dark spot with the proximal part of the preapical dark spot on vein first radial vein from 79 female progeny of iso-female lines of Anopheles calderoni generated from females collected in Valle de Cauca, Colombia

\begin{tabular}{|c|c|c|c|c|c|c|c|c|c|c|}
\hline \multirow[b]{2}{*}{ Isofamily } & \multicolumn{10}{|c|}{ Isofamily number } \\
\hline & 1 & 2 & 3 & 4 & 5 & 6 & 7 & 8 & 9 & 10 \\
\hline $1^{a}$ & 0.020 & -0.010 & 0.080 & 0.010 & 0.060 & 0.040 & 0.050 & -0.040 & 0.100 & 0.020 \\
\hline 2 & 0.040 & -0.040 & 0.110 & 0.026 & 0.090 & 0.080 & -0.060 & 0.000 & 0.040 & 0.060 \\
\hline 3 & 0.030 & 0.000 & 0.050 & 0.054 & 0.060 & 0.000 & 0.000 & 0.010 & 0.036 & 0.004 \\
\hline $4^{a}$ & 0.026 & -0.026 & 0.074 & 0.020 & 0.060 & 0.070 & 0.070 & 0.000 & 0.050 & 0.000 \\
\hline $5^{a}$ & 0.000 & -0.020 & 0.040 & 0.040 & 0.090 & 0.020 & 0.110 & 0.000 & 0.006 & 0.070 \\
\hline 6 & - & -0.020 & 0.070 & 0.060 & 0.054 & 0.030 & 0.000 & -0.040 & 0.026 & 0.050 \\
\hline 7 & - & -0.034 & 0.080 & - & 0.130 & 0.000 & 0.020 & -0.030 & -0.010 & 0.020 \\
\hline 8 & - & -0.040 & 0.050 & - & - & 0.020 & 0.000 & - & - & 0.020 \\
\hline 9 & - & -0.030 & 0.026 & - & - & - & -0.040 & - & - & 0.000 \\
\hline 10 & - & -0.050 & 0.050 & - & - & - & -0.030 & - & - & - \\
\hline Mean & 0.023 & -0.024 & 0.063 & 0.035 & 0.078 & 0.033 & 0.012 & -0.014 & 0.035 & 0.027 \\
\hline SD & \pm 0.015 & \pm 0.015 & \pm 0.024 & \pm 0.020 & \pm 0.028 & \pm 0.030 & \pm 0.052 & \pm 0.021 & \pm 0.035 & \pm 0.026 \\
\hline
\end{tabular}

$a$ : DNA-typed isofamily; SD: standard deviation. Negative or zero values signify lack of overlap.

Sequencher ${ }^{\mathrm{TM}}$ version 4.8 (Genes Codes Corporation, Ann Arbor, Michigan) and aligned in CLUSTALX (Jeanmougin et al. 1998) (Fig. 2). Similarity of the sequences generated in this study was compared with those available in GenBank using Blast (blast.ncbi.nlm.nih.gov/) and sequences were analyzed according to standard barcoding methodology (Hebert et al. 2003). Sequence statistics, calculation of pairwise distance parameters using Kimura 2-parameter algorithm (Kimura 1980) and generation of the bootstrapped neighbor-joining tree (10,000 replicates) were carried out in MEGA v.4.0 (Tamura et al. 2007).

Details of isofamily specimens of An. calderoni sequenced from Colombia $(\mathrm{n}=7)$ and wild-caught specimens from Ecuador $(n=5)$ in this study are given in Table V. In addition, one specimen each of the closely related taxa An. punctimacula [Gamboa, Panama $\left(09^{\circ} 06^{\prime} \mathrm{N}, 79^{\circ} 41^{\prime} \mathrm{W}\right)$; colls.: J Loaiza, Y Linton, F Ruiz and students of The ScholarShip LLC] and An. malefactor [Yaviza, Panama $\left(08^{\circ} 11^{\prime} \mathrm{N}, 77^{\circ} 41^{\prime} \mathrm{W}\right)$; coll.: J Loaiza] were included in the analysis, but no specimens of $A n$. guarao were available for inclusion. The COI electropherograms and specimen details (including exact localities details with georeferences, details of voucher type and housing, GenBank accessions) are available in the public records of the MBI section of the Barcode of Life Data Systems v. 2.5 (boldsystems.org) (Ratnasingham \& Hebert 2007) and appear in GenBank as barcode red flag data, indicating their high quality and voucher standards under the following accessions: An. calderoni (Colombia HQ642964-70, Ecuador HQ642971-74), An. punctimacula (Panama HQ622626) and An. malefactor (Panama HQ622625). The ITS2 sequences of An. calderoni generated in this study are available in GenBank under accessions numbers HQ622618-HQ622622.

\section{RESULTS}

\section{Morphological assessment of Colombian An. calderoni}

Adults - Nearly all the female progeny from families reared for this study exhibited characters concordant with those given in the original description of An. calderoni as follow: upper mesanepimeron with pale scales, wings with pale yellow scales mixed with white scales, distal postsubcostal pale spot on the costa and the postsubcostal pale spot on the first radial $\left(R_{1}\right)$ not contiguous, frequently separated by dark scales at their respective ends, i.e. overlap of scales of the distal part of the postsubcostal dark spot with the proximal part of the preapical dark on vein $R_{1}$ (Fig. 1A, B); scales on vein $R_{1}$ between the proximal part of the presubcostal pale and the distal postsubcostal pale generally dark (Fig. 1B), i.e. $\mathrm{R}_{1}$ in the subcostal area is usually all dark except for pale spots at the ends.

Measures of the overlap of scales of the distal part of the postsubcostal dark spot with the proximal part of the preapical dark spot of $R_{1}$ were found to be heterogeneous

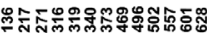

Haplotype1(COL=6) tgcggcaaaacta Haplotype2 $(\mathrm{COL}=1) \ldots . . . . \ldots$. Haplotype3 $(\mathrm{EC}=2)$ c...at..g...cg Haplotype4(EC=1) C...atg.g...cg Haplotype 5 $(E C=1)$ ca.aa.gg..ttg Haplotype6(EC=1) cataa.g..gctg

Fig. 2: alignment of unique cytochrome c oxidase subunit I gene haplotypes of 13 Anopheles calderoni from Colombia $(\mathrm{COL})(\mathrm{n}=7)$ and Ecuador $(E C)(n=6)$. Numbers above bases indicate position of variable bases along the $658 \mathrm{bp}$ fragment (709 bp with primers). Points indicate bases identical to haplotype 1 . 


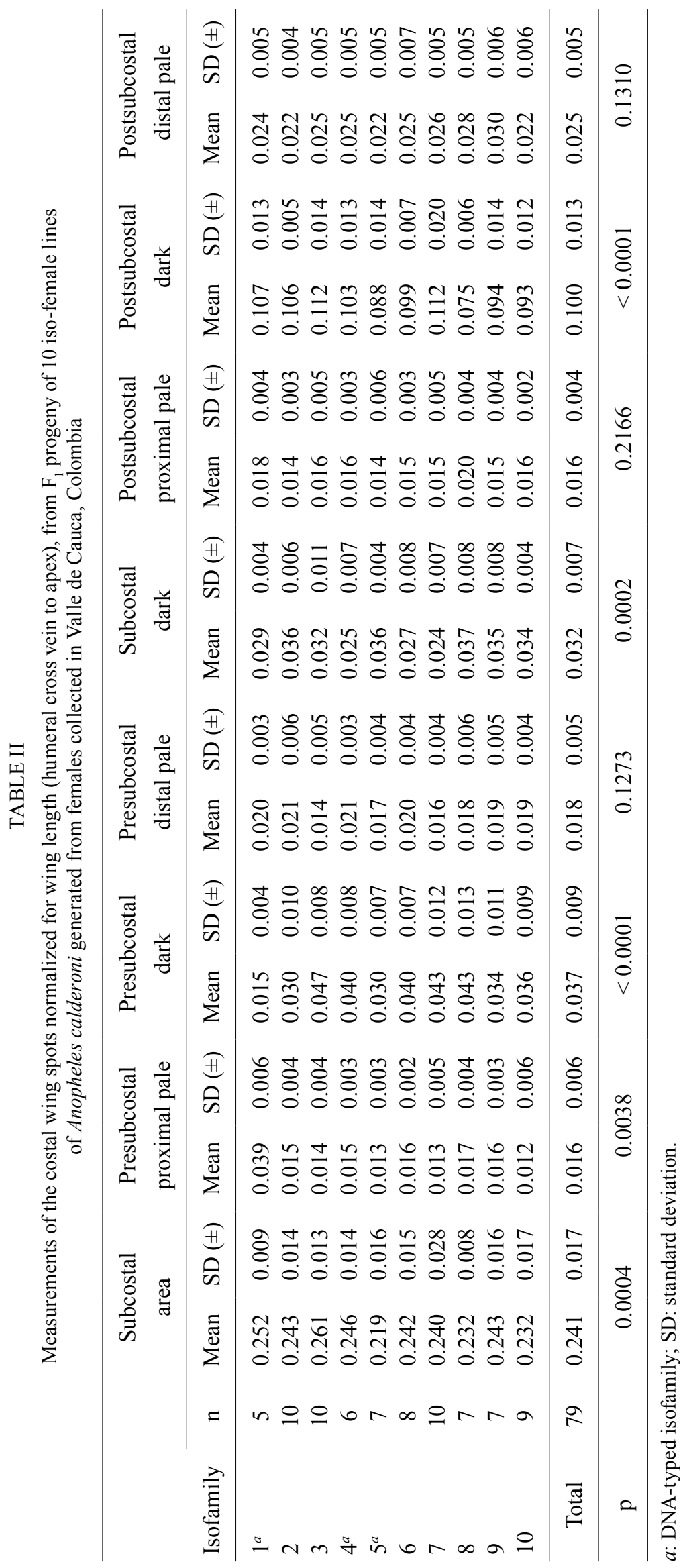


TABLE III

Measurements of the costal wing spots normalized for wing length (humeral cross vein to apex) from 79 females from 10 isofamilies of Anopheles calderoni generated from females collected in Valle de Cauca, Colombia, compared to those given in the original description of An. calderoni (Wilkerson 1991)

\begin{tabular}{|c|c|c|c|c|c|c|}
\hline \multirow[b]{2}{*}{ Wing spot } & \multicolumn{3}{|c|}{ Isofamilies (Colombia) } & \multicolumn{3}{|c|}{ Wilkerson (1991) } \\
\hline & Mean & $\mathrm{SD}( \pm)$ & Range & Mean & $\mathrm{SD}( \pm)$ & Range \\
\hline Humeral pale & 0.01 & 0.010 & $0.01-0.03$ & 0.02 & 0.010 & $0.01-0.03$ \\
\hline Humeral dark & 0.07 & 0.010 & $0.04-0.10$ & 0.09 & 0.020 & $0.03-0.12$ \\
\hline Presector pale & 0.01 & 0.000 & $0.01-0.02$ & 0.02 & 0.010 & $0.01-0.03$ \\
\hline Presector dark & 0.11 & 0.020 & $0.08-0.15$ & 0.09 & 0.020 & $0.05-0.14$ \\
\hline Sector pale & 0.07 & 0.020 & $0.03-0.10$ & 0.10 & 0.020 & $0.06-0.14$ \\
\hline Sector pale accessory & 0.04 & 0.010 & $0.02-0.07$ & 0.06 & 0.020 & $0.04-0.10$ \\
\hline Sector dark & 0.18 & 0.020 & $0.02-0.23$ & 0.15 & 0.020 & $0.11-0.18$ \\
\hline Area subcostal & 0.24 & 0.020 & $0.20-0.29$ & 0.28 & 0.020 & $0.24-0.31$ \\
\hline Presubcostal dark & 0.04 & 0.010 & $0.01-0.06$ & 0.04 & 0.010 & $0.02-0.06$ \\
\hline Presubcostal pale (proximal) & 0.02 & 0.010 & $0.01-0.05$ & 0.02 & 0.010 & $0.01-0.06$ \\
\hline Presubcostal pale (distal) & 0.02 & 0.000 & $0.01-0.04$ & 0.02 & 0.010 & $0.01-0.03$ \\
\hline Postsubcostal dark & 0.10 & 0.020 & $0.06-0.14$ & 0.10 & 0.010 & $0.07-0.12$ \\
\hline Postsubcostal pale (proximal) & 0.02 & 0.000 & $0.01-0.03$ & 0.02 & 0.010 & $0.01-0.04$ \\
\hline Postsubcostal pale (distal) & 0.02 & 0.010 & $0.02-0.04$ & 0.04 & 0.010 & $0.02-0.06$ \\
\hline Subcostal dark & 0.03 & 0.010 & $0.01-0.05$ & 0.02 & 0.001 & $0.01-0.04$ \\
\hline Preapical dark & 0.15 & 0.020 & $0.12-0.20$ & 0.13 & 0.016 & $0.10-0.18$ \\
\hline Preapical pale & 0.10 & 0.010 & $0.07-0.12$ & 0.11 & 0.010 & $0.09-0.12$ \\
\hline Preapical dark accessory & 0.05 & 0.010 & $0.01-0.07$ & 0.05 & 0.010 & $0.04-0.07$ \\
\hline Apical dark & 0.03 & 0.010 & $0.01-0.04$ & 0.02 & 0.010 & $0.01-0.03$ \\
\hline
\end{tabular}

SD: standard deviation.

TABLE IV

Variation in numbers of branches of seta 3-C and the positioning of seta 1-X with respect to the saddle in 144 specimens from 10 isofamilies of Anopheles calderoni generated from females collected in Valle de Cauca, Colombia

\begin{tabular}{|c|c|c|c|c|c|c|c|c|}
\hline \multirow[b]{2}{*}{ Isofamily } & \multirow[b]{2}{*}{$\begin{array}{c}\text { Individuals } \\
\mathrm{n}\end{array}$} & \multicolumn{4}{|c|}{$\begin{array}{c}\text { Number of branches on } \\
\text { seta } 3-\mathrm{C}\end{array}$} & \multicolumn{3}{|c|}{$\begin{array}{l}\text { Position of } \\
\text { seta } 1-X\end{array}$} \\
\hline & & Mean & Min & Max & Mode & $\mathrm{n}$ & $\begin{array}{c}\text { Saddle } \\
\%\end{array}$ & $\begin{array}{c}\text { Border } \\
\%\end{array}$ \\
\hline $1^{a}$ & 6 & 5.5 & 4 & 7 & $4-7$ & 3 & 100 & - \\
\hline 2 & 6 & 6.2 & 4 & 7 & $4-8$ & 3 & 100 & - \\
\hline 3 & 26 & 5.9 & 3 & 9 & 4 & 13 & 69.2 & 23.1 \\
\hline $4^{a}$ & 26 & 4.5 & 3 & 7 & 4 & 12 & 91.7 & 8.3 \\
\hline $5^{a}$ & 13 & 4.5 & 2 & 6 & $4-6$ & 6 & 100 & - \\
\hline 6 & 5 & 6.6 & 5 & 7 & 5 & 3 & 100 & - \\
\hline 7 & 19 & 5.4 & 2 & 7 & 6 & 10 & 70 & 30 \\
\hline 8 & 12 & 5.8 & 4 & 8 & 6 & 5 & 60 & 40 \\
\hline 10 & 15 & 4.7 & 1 & 6 & 6 & 7 & 85.7 & 14.3 \\
\hline 11 & 5 & 7.4 & 1 & 11 & - & 2 & 50 & 50 \\
\hline 12 & 4 & 5.5 & 5 & 6 & $5-6$ & 2 & 100 & - \\
\hline Total & 137 & 5.4 & 1 & 11 & 6 & 66 & 81.8 & 16.7 \\
\hline
\end{tabular}

$a$ : DNA-typed isofamilies. 
among families $(p<0.0001)$ and variable even among female siblings (Table I). This value is positive when there is overlap in the spots, but can also have a value of zero when the ends of the spot are immediately adjacent and a negative value when the spots are clearly separated (Fig. 1B). Overall, eight of the 10 isofamilies examined exhibited overlapping spots (0.003-0.024 mm), however many of the individuals in isofamily 2 and some from isofamilies 7-9 showed either no overlap but immediately adjacent spots or clear separation of the spots (Table I). An even alignment of the postsubcostal spot on $\mathrm{C}$ and $\mathrm{R}_{1}$, reportedly typical of all other Arribalzagia Series species (Suárez et al. 1988, Wilkerson 1990, 1991, González \& Carrejo 2007), was not observed in the An. calderoni specimens examined here. Considering the above observations, it is necessary to add a clarification of the original description of this character as follows: "distal postsubcostal pale spot on vein $\mathrm{C}$ generally not contiguous with the postsubcostal pale on vein $R_{\text {, }}$, separated (generally) or not by dark scales of the distal part of the postsubcostal dark and the proximal part of preapical dark on $\mathrm{R}_{1}$ ". For those specimens that agree with the remaining characters yet where the aforementioned overlap does not occur, it is possible complement species identification by examination of the scales between the proximal presubcostal pale and the distal postsubcostal pale spots located on $\mathrm{R}_{1}$. These are usually all dark in An. calderoni, whereas they are predominantly pale in An. punctimacula, An. malefactor and An. guarao (Wilkerson 1991).

Analysis of costal spots within the isofamilies revealed that some specimens did not comply with a normal distribution, even after data transformation using wing length; hence a non-parametric Kruskal-Wallis test was used to compare the averages of these measurements among isofamilies.

Statistically significant differences were found when comparing lengths of the subcostal area (Fig. 3) as a whole among the isofamilies; yet, the relative size comparisons of individual spots within this area, i.e. the size of the most distal presubcostal pale spot, and the proximal and distal postsubcostal pale spots, did not statistically differ amongst isofamilies (Table II). Furthermore, the average values among isofamilies (Table III) were very similar to those presented in the original description (Wilkerson 1991).

The band or spot on hindtarsomere 5 was generally found not to be as pale as in the original description (Wilkerson 1991). Instead it was observed as a darker band, sometimes grayish or pale brown and was not well defined in $91.1 \%$ of the progeny specimens examined. This darker band was also noted in $94.6 \%$ of specimens collected in human landing catches from the same locality (Valle de Cauca, $\mathrm{n}=37$ ).

The original description of An. calderoni makes no reference to variation in the pale and dark spots of the 4th hindtarsomere 4, which are otherwise widely employed as diagnostic characters in several morphological keys for species of the Arribalzagia Series (Gorham et al. 1973, Wilkerson et al. 1990, González \& Carrejo 2007). There are generally five spots of varying length on hindtarsomere 4: two dark and three pale (basal, apical and central). Spots reportedly differ in length, with the two pale spots (basal, apical) being smaller than the dark spots. In $91.6 \%$ of Colombian An. calderoni examined $(\mathrm{n}=79)$, the central pale spot separated the two dark spots; whereas in the remaining specimens the central pale spot was not clear, allowing the two dark spots to merge and appear more like a band. The central pale spot was found to be of variable width, and was mostly light grey in color. This character was even found to be variable between legs of the same individual therefore we discourage the further use of this character for species diagnosis in the Arribalzagia Series.

Larvae - The number of branches in seta 3-C and the position of seta 1-X were assessed in all 144 specimens from 10 isofamilies (Table IV). That seta 1-X is not present on the saddle is a shared characteristic of both $A n$. punctimacula and An. calderoni. In $98.2 \%$ of progeny examined, seta 1-X was not found on the saddle itself, with $81.5 \%$ attached outside this structure altogether and $16.7 \%$ placed on its border (Table IV). Most commonly, An. calderoni larvae exhibited 4-7 branches on seta 3-C (range 1-11; mean 5.4; mode 6). The mean number of branches is slightly higher than the 4.2 reported in the original description (Wilkerson 1991), most probably due to increased sample size. An. punctimacula differs significantly in having an average of 11.5 branches hence the combination of these two characters allows morphological differentiation of larval An. calderoni and An. punctimacula.

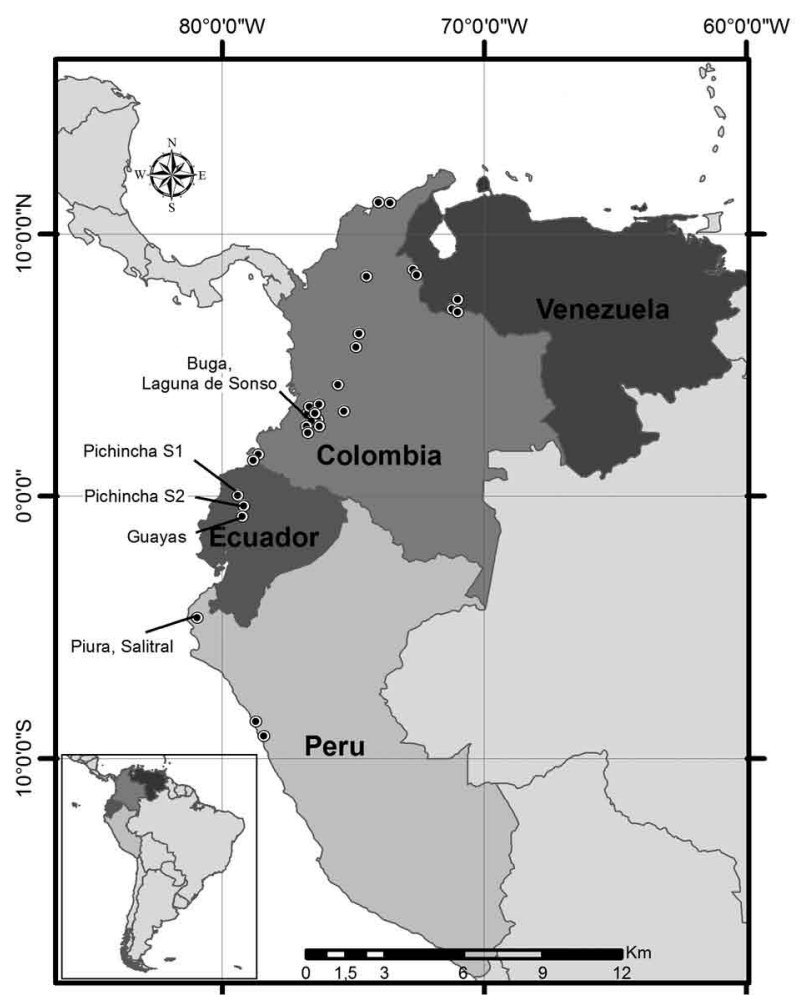

Fig. 3: map indicating the known distribution of Anopheles calderoni in Colombia, Ecuador, Peru and Venezuela, based on morphological and molecular verification, following this study and those of Wilkerson (1991) and Rubio-Palis and Moreno (2003). 


\section{DISCUSSION}

Revision of MUSENUV archive specimens - Retrospective identification of archive specimens of An. punctimacula and An. malefactor held in the MUSENUV revealed a significant proportion of specimens were infact $A n$. calderoni. Specimens of An. calderoni were detected in collections from 1948-2009, in 35 localities in 20 municipalities, representing 12 departments of Colombia (Supplementary data). Although the distribution of An. calderoni in Colombia appears predominantly coastal (both on the Pacific and Atlantic coasts) (Fig. 3), some of the departments (e.g. Tolima) are far inland. Additionally, several collection sites in Valle de Cauca and Quindio were over $1000 \mathrm{~m}$ in altitude (Supplementary data), considerably higher than the $250 \mathrm{~m}$ limit previously reported for early reports of $\mathrm{An}$. calderoni in Peru (Wilkerson 1991) and 200-400 m reported in Venezuela (Rubio-Palis \& Moreno 2003). Rather our data supports the findings of Calderón et al. (1995) who reported An. calderoni from sea level to $1080 \mathrm{~m}$ in Peru, suggesting that the distribution of An. calderoni could be considerably more extensive than at first thought.

Molecular characterization of An. calderoni ITS2 rDNA sequences generated from two specimens [PE400(2)-29, PE400(2)-31] belonging to the type series of An. calderoni from Salitral (Wilkerson 1991) were identical to those from three specimens from Ecuador (Table V), thus verifying the new country record of $A n$. calderoni in Ecuador. Correlation of the 658 bp COI DNA barcode of one of the verified Ecuadorian An. calderoni specimens (EC229-1) allowed the confirmation the conspecific identity of additional wild-caught adults from two other sites in Ecuador (Guayas, $n=4$, Pichincha, $\mathrm{n}=1)$ and progeny broods collected in Valle de Cauca, Colombia ( $\mathrm{n}=7$ from isofamilies 1,4 and 5) (Table $\mathrm{V})$, used in the morphological assessment (Table V).

In total, DNA barcodes were generated for 12 specimens (Colombia, $\mathrm{n}=7$, Ecuador, $\mathrm{n}=5$ ), which varied in AT richness from $66-66.5 \%$. Six unique haplotypes were determined, as follows: haplotypes $1(\mathrm{n}=6)$ and $2(\mathrm{n}=1)$ (both Valle de Cauca, Colombia), haplotype 3 [Guayas (n $=1)$ and Pichincha $(\mathrm{n}=1)$, Ecuador] and haplotypes 4-6 ( $\mathrm{n}$ $=1$, each one from Guayas, Ecuador) (Figs 2, 3). Within Colombia, haplotypes 1 and 2 varied by only one base (A/G at base 319) (Fig. 2). Overall, 13 (1.97\%) variable bases were noted, 10 of which were parsimony informative. Mean pairwise (K2P) sequence diversity within $A n$. calderoni was $0.70 \%$, well within values of intraspecific variation reported for the barcoding region in other mosquito species (Cywinska et al. 2006, Kumar et al. 2007, Azari-Hamidian et al. 2010). Haplotypes were unique by country, with mean intra-country pairwise distances of $0.04 \%$ and $0.77 \%$ within Colombian and Ecuadorian specimens, respectively, and an overall mean inter-country sequence divergence of $1.03 \%$. Amino acid translation of the COI sequences revealed that all nucleotide changes were synonymous, suggesting that these represent population level differences only.

Differentiation of An. calderoni, An. punctimacula, An. malefactor and An. guarao - Given that An. calderoni has often been misidentified as An. punctimacula in
Colombia (herein), we set out to assess the utility of DNA barcodes for species differentiation between these species and other closely related taxa - An. malefactor and An. guarao. No specimens of An. guarao were available for molecular comparison, but the morphological distinctiveness of this species makes it unlikely to be confused with An. calderoni. The robust boot strap values illustrated on the neighbor-joining tree generated using the COI barcode data of An. calderoni, An. punctimacula and An. malefactor confirmed the separate species status of these taxa (Fig. 4). In comparison to the $0.70 \%$ interspecific variation noted within An. calderoni, interspecific comparisons with those of Panamanian An. punctimacula and An. malefactor generated in this study, revealed $5.8 \%$ and $10.9 \%$ variation, respectively (Fig. 4). COI barcodes of An. malefactor $(67.7 \%$ AT) were most similar to those of An. punctimacula $(67.1 \%$ AT), differing by $9.6 \%$.

Neither An. calderoni nor An. malefactor are currently represented in GenBank and thus these sequences also comprise the first DNA sequences reported for these species. Although the GenBank entry AF417719 of Sallum et al. (2002) partially overlapped our An. punctimacula sequence by 93 bases, the sequences generated herein represent the first published DNA barcodes for that species. This study shows that DNA barcodes will aid correct identification of An. calderoni, An. malefactor and An. punctimacula in future studies and will allow the vector status of An. calderoni and An. malefactor to be more accurately assessed.

DNA verification of Ecuadorian and Colombian specimens as An. calderoni along with the morphological reassessment of archived MUSENUV specimens significantly adds to the knowledge of the distribution of An. calderoni in Latin America (Fig. 3). Given that the known distribution of An. calderoni now includes Ecuador and Colombia, as well as Peru and Venezuela, and its prior taxonomic confusion with An. punctimacula and An. malefactor, it is now prudent to carry out further collections to determine the true distributions and specific roles in malaria transmission of these three species across the Neotropical Region.

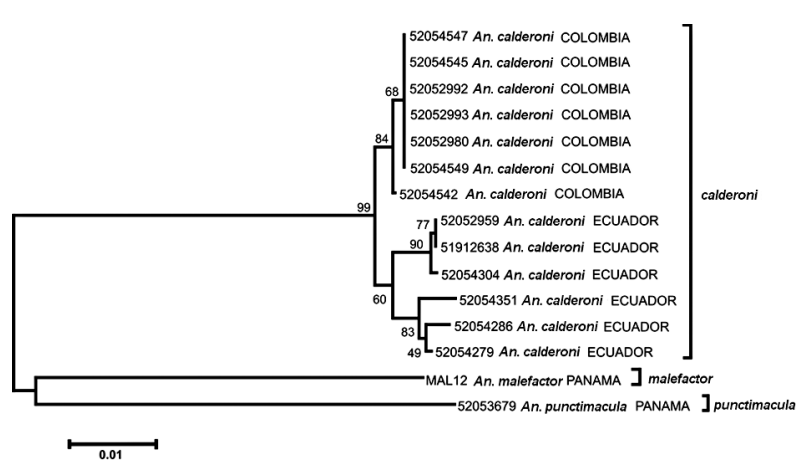

Fig. 4: neighbor-joining tree of Anopheles calderoni, Anopheles punctimacula and Anopheles malefactor based on $658 \mathrm{bp}$ of the mtDNA cytochrome c oxidase subunit I gene gene. The tree was constructed using 10,000 replicates of pairwise genetic distances generated using the Kimura 2-parameter distance algorithm. Bootstrap confidence limits are shown on tree labels. 
定
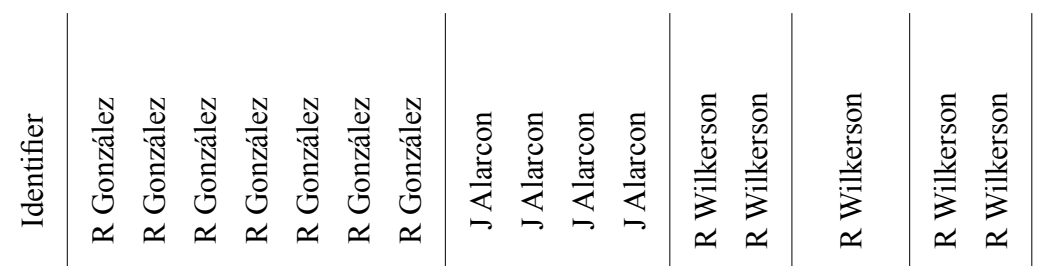

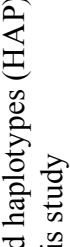

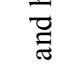

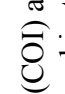

急

焉

:

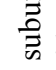

क

:

0.

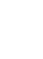
$>\hat{\jmath}$ 되

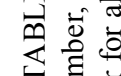

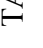

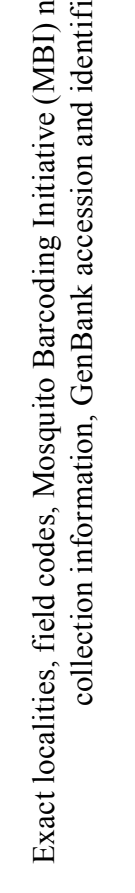




\section{ACKNOWLEDGEMENTS}

To La Universidad del Valle, Colombia, to the Mosquito Barcoding Initiative, to the owner, officers and crew of The ScholarShip, for supporting this research through provision of laboratory infrastructure and operational assistance, to Property Spy PLC, for Molecular costs funded through the generous donations, to the anonymous friends of the Natural History Museum, to further the activities of the Mosquito Barcoding Initiative. Parts of this research were performed at the Smithsonian Institution under a Memorandum of Understanding between the Walter Reed Army Institute of Research and the Smithsonian Institution, with institutional support provided by both organizations. The material contained within this manuscript has been reviewed by the Walter Reed Army Institute of Research. There is no objection to its presentation and/or publication. The opinions or assertions contained herein are the private views of the author, and are not to be construed as official, or as reflecting true views of the Department of the Army or the Department of Defense.

\section{REFERENCES}

Anduze PJ, Capdevielle A 1949. Anopheles (Anopheles) guarao sp. nov. Bol Ent Venezol 8: 119-124.

Azari-Hamidian S, Linton Y-M, Abai MR, Ladonni H, Oshaghi MA, Hanafi-Bojd AA, Moosa-Kazemi SH, Shabkhiz H, Pakari A, Harbach RE 2010. Mosquito (Diptera: Culicidae) fauna of the Iranian islands in the Persian Gulf. J Nat Hist 44: 913925.

Belkin JN, Hogue CS, Galindo P, Aitken THG, Schick RX, Powder WA 1965. Mosquito studies (Diptera, Culicidae). II. Methods for the collection, rearing and preservation of mosquitoes. Contrib Am Entomol Inst 1: 19-78.

Calderón G, Curaca A, Llancari J, Napán M, Sipan F 1974. Distribución geográfica de los vectores de malaria en el Perú. Rev Per Med Tropical 2: 88-91.

Calderón G, Fernández R, Valle J 1995. Especies de la fauna anofelina, su distribución y algunas consideraciones sobre su abundancia e infectividad en Perú. Rev Peru Epidem 8: 5-23.

Collins FH, Paskewitz SM 1996. A review of the use of ribosomal DNA (rDNA) to differentiate among cryptic Anopheles species. Insect Mol Biol 5: 1-9.

Cywinska A, Hunter FF, Hebert PD 2006. Identifying Canadian mosquito species through DNA barcodes. Med Vet Entomol 20: 413-424.

Folmer O, Black M, Hoeh W, Lutz R, Vrijenhoek R 1994. DNA primers for amplification of mitochondrial cytochrome c oxidase subunit I from diverse metazoan invertebrates. Mol Mar Biol Biotechnol 3: 294-299.

González R, Carrejo NS 2007. Introducción al estudio taxonómico de Anopheles de Colombia. Claves y notas de distribución, Universidad del Valle, Cali, 237 pp.

Gorham JR, Stojanovich CJ, Scott HG 1973. Illustrated key to the anopheline mosquitoes of western South America. Mosq Syst 5: $97-156$
Harbach RE 2004. The classification of genus Anopheles (Diptera: Culicidae): a working hypothesis of phylogenetic relationships. Bull Entomol Res 94: 537-553.

Hebert PDN, Cywinska A, Ball SL, de Waard JR 2003. Biological identifications through DNA barcodes. Proc R Soc Lond 270: 313-321.

Jeanmougin F, Thompson JD, Gouy M, Higgins DG, Gibson TJ 1998. Multiple sequence alignment with ClustalX. Trends Biochem Sci 23: 403-405.

Kimura M 1980. A simple method for estimating evolutionary rates of base substitutions through comparative studies of nucleotide sequences. J Mol Evol 16: 111-120.

Kroeger A, Alarcón J 1993. Malaria en Ecuador y Peru y estrategias alternativas de control, Abya-Yala, Quito, $316 \mathrm{pp}$.

Kumar NP, Rajavel AR, Natarajan R, Jambulingam P 2007. DNA barcodes can distinguish species of Indian mosquitoes (Diptera: Culicidae). J Med Entomol 44: 1-7.

Levi-Castillo R 1949. Atlas de los anofelinos sudamericanos, Sociedad Filantropica del Guayas, Guayaquil, 207 pp.

Linton Y-M, Harbach RE, Chang MS, Anthony TG, Matusop A 2001. Morphological and molecular identity of Anopheles (Cellia) sundaicus (Diptera: Culicidae), the nominotypical member of a malaria vector species complex in Southeast Asia. Syst Entomol 26: 357-366.

Ratnasingham S, Hebert PD 2007. BOLD: the Barcode of Life Data System (http://www.barcodinglife.org). Mol Ecol Notes 7: 355-364.

Rubio-Palis Y, Moreno JE 2003. Primer registro de Anopheles (Anopheles) calderoni (Diptera: Culicidae) en Venezuela. Entomotropica 18: 159-161.

Russell PF, West LS, Manwell RD, MacDonald G 1963. Practical malariology, 2nd ed., Oxford University Press, London, 750 pp.

Sallum MAM, Schultz TR, Foster PG, Aronstein K, Wirtz RA, Wilkerson RC 2002. Phylogeny of Anophelinae (Diptera: Culicidae) based on nuclear ribosomal and mitochondrial DNA sequences. Syst Entomol 27: 361-382.

Suárez MF, Quiñones M, Fleming GA, Robayo M 1988. Guía introductoria a la morfología de Anopheles y clave para determinación de las principales especies de Colombia, DCD, Ministerio de Salud, Bogotá, $120 \mathrm{pp}$.

Tamura K, Dudley J, Nei M, Kumar S 2007. MEGA4: Molecular Evolutionary Genetics Analysis (MEGA) software version 4.0. Mol Biol Evol 24: 1596-1599.

Wilkerson RC 1990. Redescriptions of Anopheles punctimacula and An. malefactor (Diptera: Culicidae). J Med Entomol 27: 225-247.

Wilkerson RC 1991. Anopheles (Anopheles) calderoni n. sp., a malaria vector of the Arribalzagia series from Peru (Diptera: Culicidae). Mosquito Syst 23: 25-38.

Wilkerson RC, Peyton EL 1990. Standardized nomenclature for the costal wing spots of the genus Anopheles and other spotted-wing mosquitoes (Diptera: Culicidae). J Med Entomol 27: 207-224.

Wilkerson RC, Strickman D, Litwak TR 1990. Illustrated key to the female anopheline mosquitoes of Central America and Mexico. J Am Mosq Control Assoc 6: 7-34. 
Collection details of specimens of Anopheles calderoni retrospectively identified in the collections of the Entomology Museum of the Universidad del Valle, Colombia

\begin{tabular}{|c|c|c|c|c|c|}
\hline Department & Municipality & Locality & $\begin{array}{l}\text { Elevation } \\
\text { (m) }\end{array}$ & $\begin{array}{l}\text { Collection } \\
\text { date }\end{array}$ & Collector \\
\hline \multirow{3}{*}{ Antioquia } & Gómez Plata & El Brasil & 244 & 10 May1984 & SEM \\
\hline & Puerto Nare & El Pescado & 270 & 4 Oct 1983 & SEM \\
\hline & Santafe de Antioquia & Paso Real & 666 & 17 Mar 1984 & SEM \\
\hline Bolívar & Achí & Platanal & 23 & 26 Jun 1984 & SEM \\
\hline \multirow{2}{*}{ Caldas } & La Dorada & Guarinocito & 200 & unknown & SEM \\
\hline & Puerto Tejada & Perico Negro & 990 & unknown & SEM \\
\hline Cauca & Villarica & Água Azul & 990 & $\begin{array}{c}18 \text { Feb } 2005 \\
1 \text { Mar } 2006\end{array}$ & Curso de E. Médica \\
\hline Chocó & Riosucio & Caño Pavas & 4 & 5 Jun 1981 & SEM \\
\hline Guajira & Riohacha & Las Flores & 9 & 22 Jun 1986 & H Ramirez (SEM) \\
\hline Magdalena & Santa Marta & Guachaca & 18 & 2 May 1983 & Derrueco (SEM) \\
\hline \multirow{8}{*}{ Nariño } & \multirow{8}{*}{ Tumaco } & Brazo Rio Mira & 15 & 7 Apr 1986 & SEM \\
\hline & & Bucheli & 10 & 9 Jun 1987 & Cortés (SEM) \\
\hline & & Chajal & 9 & 7 Jun 1987 & Cortés (SEM) \\
\hline & & Chilví-Línea & 15 & $\begin{array}{l}\text { 17 Jun } 1986 \\
\text { 22 Jul } 1986 \\
\text { 21 Jul } 1986 \\
\text { 23 Jul } 1986\end{array}$ & Cortés (SEM) \\
\hline & & El Descalzadero & 15 & 28 Feb 1984 & SEM \\
\hline & & Ing. del Carmen & 15 & $\begin{array}{c}23 \text { Jun } 1987 \\
\text { 3 Jul } 1987 \\
\text { 10 Jul } 1987 \\
\text { 16 Jul } 1987\end{array}$ & Cortés (SEM) \\
\hline & & Ing. del Guadual & 15 & 18 Jun 1987 & Cortés (SEM) \\
\hline & & Nueva Union 2 & 15 & 1 Apr 1986 & Castillo (SEM) \\
\hline \multirow{3}{*}{$\begin{array}{l}\text { Norte de } \\
\text { Santander }\end{array}$} & \multirow{3}{*}{ Tibú } & Puerto Barco & 56 & $\begin{array}{l}17 \text { Jun } 1986 \\
\text { 26 Jun } 1987\end{array}$ & Pabón (SEM) \\
\hline & & Isla La Ceiba & 35 & 24 Sep 1986 & SEM \\
\hline & & Caño Castillo & 60 & Sep 1983 & SEM \\
\hline Quindio & Quimbaya & La Montaña del Ocaso & 1100 & 13 Nov 2003 & P Lopez \& I Valderrama \\
\hline Tolima & Ataco & Bocas de S. Pedro & 613 & 30 Nov 1981 & D Tique (SEM) \\
\hline
\end{tabular}




\begin{tabular}{|c|c|c|c|c|c|}
\hline Department & Municipality & Locality & $\begin{array}{c}\text { Elevation } \\
\text { (m) }\end{array}$ & $\begin{array}{l}\text { Collection } \\
\text { date }\end{array}$ & Collector \\
\hline \multirow{17}{*}{ Valle del Cauca } & \multirow{7}{*}{ Buga } & & & & R González, N Carrejo, \\
\hline & & & & 7 Jun 2007 & DM Lucumí, CX \\
\hline & & Laguna de Sonso & 960 & 9 Jul 2007 & Restrepo, \\
\hline & & & & May 2009 & DM Montoya \& C \\
\hline & & & & & Salas \\
\hline & & El Vinculo & 970 & 2008 & LM Martínez \\
\hline & & Chambimbal, El Cedral & 928 & May 2009 & D M Montoya \\
\hline & Bugalagrande & El Pital (Humedal) & 926 & 29 Apr 2009 & DM Montoya \\
\hline & \multirow{2}{*}{ Candelaria } & El Cabuyal & 1005 & $\begin{array}{l}\text { May } 2006 \\
7 \text { May } 2007\end{array}$ & $\begin{array}{c}\text { MH Cuellar \& LM } \\
\text { Martínez }\end{array}$ \\
\hline & & El Otoño & 1005 & May 2008 & $\begin{array}{c}\text { DM Cundumí \& CX } \\
\text { Restrepo }\end{array}$ \\
\hline & \multirow{3}{*}{ Florida } & Chocosito & 1045 & $\begin{array}{l}15 \text { May } \\
2007\end{array}$ & R González \\
\hline & & & & May 1948 & \\
\hline & & Florida (Cab) & 1030 & $\begin{array}{c}20 \text { Aug } \\
1948\end{array}$ & A Patiño (SEM) \\
\hline & Jamundí & Urb. Terranova & 980 & 28 Apr 2009 & V Cerón \\
\hline & \multirow[b]{2}{*}{ Palmira } & Ciat & 962 & Oct 2007 & LM Martínez \\
\hline & & San Isidro-El Bolo & 980 & $\begin{array}{c}15 \text { May } \\
2005 \\
24 \text { Nov } \\
2007\end{array}$ & $\begin{array}{c}\text { D Gómez \& LM } \\
\text { Martínez }\end{array}$ \\
\hline & Tulúa & Mate Guadua & 1113 & 28 Apr 2006 & $\begin{array}{c}\text { H Cadena, NJ Mina \& } \\
\text { C Robledo }\end{array}$ \\
\hline
\end{tabular}

SEM: Servicio de Erradicación de la Malaria, Colombia. 